\title{
Experiences of distance doctoral supervision in cross-cultural teams
}

Reem Alebaikan*, Yvonne Bain+ and Sarah Cornelius+

* Corresponding author. Curriculum and Instruction Department, School of Education, King Saud University, Riyadh, KSA ebaikan@ksu.edu.sa

+ School of Education, University of Aberdeen, King's College, Aberdeen, AB24 5UA, UK

yvonne.bain1@abdn.ac.uk@yvonnebain s.cornelius@abdn.ac.uk, @sarahcornelius 


\title{
Experiences of distance doctoral supervision in cross-cultural teams
}

\begin{abstract}
In distance cross-cultural supervision scenarios $\mathrm{PhD}$ students are supported by supervisors located in different cultural contexts, which may, or may not be, the same as that of the student. Very little research has been conducted into experiences of crosscultural supervision. This paper aims to address this gap by exploring opportunities and challenges for students and supervisors. Participants were Saudi Arabian students, and UK and Saudi based supervisors. It is informed by qualitative research into the experiences of students and supervisors. Investigation of three main areas - roles and expectations, communications and technology, and personal and professional development - revealed common issues, and some specific to either students or supervisors. These include language, feedback, technology and professional learning and align with 'intensifiers' identified as making supervision complex or difficult for international PhD students (Winchester-Seeto et al. 2014). However, other issues were also identified which need to be discussed openly to ensure that the potential benefits of cross-cultural supervision are realised.
\end{abstract}

Keywords: PhD supervision, cross-cultural supervision, international PhD experiences 


\section{Introduction}

Our interest in the issue of cross-cultural supervision at a distance stems from our own professional experiences. In recent years we have encountered and participated in a number of internationally distributed cross-cultural $\mathrm{PhD}$ teams. These have included teams with one supervisor in Europe and another supervisor and the student in the Middle East; with a supervisor in Europe and a student in Central America; and with two supervisors in different European countries and the student in a third European country. Myriads of other possibilities for team composition exist and scenarios are almost always complicated further by the complex personal, educational and employment histories of participants. These shape individual identities and inform expectations and experiences of supervision. This study was initiated to help us develop a wider understanding of student and supervisor experiences of $\mathrm{PhD}$ supervision at a distance in cross-cultural contexts to support our own practice and that of others.

The uptake of distance supervision has been driven in part by financial issues (for example where overseas stays are prohibitively expensive), by the development of innovative models for study (including blended and part time routes) and the needs of particular students (such as those in professional settings or with family commitments). The emergence of ubiquitous, easy to use technologies allowing synchronous online communication has played a part in supporting such initiatives, facilitating interaction and allowing remote engagement in supervision meetings and research community activities.

All supervision scenarios involve differences of identity (Acker, 2011), and culture is always important (Manathunga, 2007). Palfreyman (2007) recognises that when students and educators move internationally cultural issues can be highlighted and new challenges and opportunities for learning created. For those working at a distance challenges can be 'cultural, professional, personal and intellectual' (Nasiri \& Mafakeri, 2015, p.1962). Cross-cultural distance learning scenarios are rarely considered in the literature so this paper attempts to illuminate some of the challenges and opportunities for students and supervisors to support our understanding of effective professional practice in this area. In addition, the paper contributes to calls for better understanding of joint supervision, both from the student and supervisor perspective (Lahenius \& Ikävalkoa, 2012).

The challenge of drawing on a limited portfolio of relevant experiences to help develop practice has been recognised for Masters supervisors (Nicol \& Cornelius, 2017), and this is likely to be even more acute with respect to $\mathrm{PhD}$ supervision. In addition, every student and cultural context is different, so practice has to be adapted for each new scenario. Thus, this research took an interpretative stance. We recognised the difficulty of making generalisations regarding the lived experiences of diverse individuals, so attempted to shed light on experience through the use of rich, thick descriptions (Creswell, 2009; Creswell and Miller, 2000). This study drew on experiences related primarily, but not exclusively, to the Saudi Arabia context, where a government funded programme (the External Joint Supervision Programme) has supported female $\mathrm{PhD}$ candidates to study at a distance guided by both local and external supervisors. 


\section{Issues in distance and cross-cultural supervision}

Whilst there is little research specifically on distance cross-cultural supervision, there is a wealth of evidence on the issues faced by international students, and on $\mathrm{PhD}$ supervision more generally. Research literature highlights issues arise in relation to culture, student expectations and language (Winchester-Seeto et al. 2014).

Cultural issues have been one area of focus, perhaps because, as Grant and Manathunga (2011) suggest, supervision across cultures 'becomes a pedagogical site of rich possibility as well as, at times, a place of puzzling and confronting complexity' (p.351). Like the authors contributing to Palfreyman (2007) we view culture as being not about particular behaviours or objects, but as being linked to ways of knowing, patterns of behaviour and meanings that are learnt from or adopted within the groups to which people belong (Whitten \& Hunter, 1992). However, we need to be aware of the dangers in overgeneralising about groups and it is unhelpful to think that all $\mathrm{PhD}$ students from a particular geographical or national background share common characteristics, or think and act in the same way. Previous work suggests that $\mathrm{PhD}$ students may contradict stereotypes. For example, Manathunga (2007) found that Asian students are not always less independent than Western students.

It could be argued that all $\mathrm{PhD}$ students engaged in international distance learning will undergo elements of the process of intercultural transition. This process of becoming part of a new culture may include elements such as socialisation, challenges to identity and acknowledgment of difference (Palfreyman, 2007). Palfreyman (2007) suggests that supervisors may also engage in this process to some extent, as they enter into the world of their students.

The social space where cultures 'meet, clash and grapple with each other, often in highly asymmetrical relations of domination and subordination' (Pratt, 1992 p. 4) can be thought of as a contact zone (Pratt, 1992; Manathunga, 2007). For distance learners, contact zones are predominantly online and enabled using tools such as Skype, Virtual Classrooms, Google Hangouts, WhatsApp or other communication and social networking tools. Based on a review of literature, Maor, Ensor \& Fraser (2016) suggest that Web 2.0 tools support dialogue and interaction, and allow collegial and collaborative development of projects: they support a trend towards participatory pedagogies. But issues of power are significant in these spaces. For instance, institutional systems may be mandated for supervisory meetings, or one party in the relationship may be able to dictate the choice of system. The language and terminology within a system may reflect a particular pedagogical approach (or none) and privilege certain users. Cornelius (2014), for example, noted power issues arising from the terminology and underlying model in some virtual classroom software. The exchange of information may also be affected if there are differences in computer literacy between supervisor and student (Nasiri and Mafakhari, 2015), an issue also identified in distance Masters supervision (Cornelius \& Nicol, 2016).

Trahar (2011) suggested that the principles of good supervision are applicable 'irrespective of where we come from' (p.6). However, she also notes that important differences need to be established and recognised when a doctoral researcher is 'not local'. Two issues she highlighted were student expectations and culture shock. All PhD students have expectations formed as a result of previous academic and professional experiences, and these may be subtle 
and difficult to articulate. Trahar identifies specific expectations encountered by international students. These include the expectation of working in a non-native language; of an informal relationship with the supervisor; and of personal sacrifice (for example leaving family behind). Distance study may help PhD students avoid some aspects of personal sacrifice (such as leaving their family), although all PhD students (particularly part time students) forfeit elements of their personal and social lives to devote time and energy to their studies (Abiddin, Ismail \& Ismail, 2011). However, even at a distance, culture shock (the feeling of disorientation in a culture different from your own which results from challenges to personal beliefs and values) may impact on students and on supervisors in cross-cultural settings.

Working in a non-native language is not an issue specific to cross-cultural supervision, but is an issue identified as an 'intensifier' for international students (Winchester-Seeto et al., 2014). Where one or more parties are not fluent in the language of communication, or trained under a different academic system, a 'linguistic gap' may exist (Nasiri \& Mafakhiri, 2015). Language issues can also impact on the building of supportive relationships between the student and supervisor. For example, Nasiri and Mafakhari (2015) note that conversations may be formal where there is a lack of personal knowledge between student and supervisor, and this may make informal discussion difficult. Yet it may be informal dialogue that is particularly important in achieving relationships based on mutual understandings of diverse cultural contexts. Trahar (2011) provides an example of arriving through dialogue with a Muslim student at a place where disparate beliefs and values could be acknowledged and celebrated, whilst similarities could be recognised.

Other commonly identified issues include entrenched expectations for academic writing which can be difficult to shift, expectations of direction and instruction from supervisors (Ali, Watson \& Dhingra, 2016), and difficulties challenging supervisors perceived as senior and expert (Pyhältö, Vekkaila \& Keskinen, 2012). Differences in expectations in terms of the feedback processes or the nature of the feedback and the way in which feedback is perceived, are also highlighted in the literature. Guerin and Green (2015) highlight the issues that arose, sometimes with devastating consequences, as PhD students struggled to develop their skills in engaging in academic discourse. Where a single voice from a supervisory team was lacking, they often felt on the periphery of any debate between supervisors about their work, which in turn left them feeling that their academic identity was under threat. Similarly, Olmos-López and Sunderland's (2016) study reported that some students disliked conflicting feedback from supervisors and felt burdened by trying to address different comments, although most liked having feedback from different perspectives. McApline (2013) also found that there were tensions in differences in expectations for feedback: '...students wanted feedback that was focused, specific, included suggestions for more reading as well as characterised overall progress' ( $p$ 263). There is a need to strike a balance between academic challenge and disagreement, presenting a united message to support the PhD student's progress (Guerin \& Green, 2015; Olmos-López \& Sunderland, 2016), and helping supervisors develop a metalanguage to discuss writing and reading with the students (McAlpine, 2013).

The identification of 'intensifiers' which impact on the experiences of international $\mathrm{PhD}$ students (Winchester-Seeto et al 2014) and evidence that there are additional issues in distance cross-cultural scenarios which impact on both students and supervisors points to a need for further evidence to help develop effective practice. Supervisors, including the authors of this paper, rarely have experience of being supervised in a cross-cultural situation before embarking 
on supervision themselves, so this paper aims to provide insights into both positive and challenging aspects of these scenarios.

\section{Research approach}

This project adopted an interpretivist approach, and employed grounded, qualitative methods for collecting and analyzing rich descriptive data. The three authors engaged in reflective dialogue to surface their experiences of distance supervision in cross-cultural contexts. Importantly however, participants of the study were recruited through personal contacts and recommendations, using a 'snowball' sampling approach. Three students and two supervisors participated. Students were female, part time students undertaking research in work related topics (see Table 1) to gain a PhD from a UK University. They were all Saudi Arabian and had supervisors located in the UK and Saudi Arabia. For two of the students the PhD was their first study programme in English. All were participants in the EJSP programme who had the opportunity to spend some time (normally at least eight weeks per year) in the UK, but undertook the majority of their PhD studies as distance students. They were not our own students. Two supervisors were interviewed, one from the UK and one from Saudi Arabia. The Saudi supervisor was the internal supervisor for one of the interviewed students. The UK supervisor had not supervised any EJSP students. Both supervisors had over 20 years experience working in Higher Education. Tables 1 and 2 summarise interviewee characteristics.

$<$ Insert Table 1 and Table 2 here>

Data were collected in 2014-16 using reflective student logs and semi-structured interviews with students and supervisors who had experience of distance supervision. One student completed a log and interview. The other students and supervisors participated only in interviews. Advantage was taken of opportunities to meet with students and supervisors in person where possible, but interviews were also conducted using Skype and Blackboard Collaborate. A semi-structured reflective conversation about the experiences of distance supervision in cross-cultural contexts between the researchers also contributed data to the study.

Issues of language were considered during the design of the research. Students were invited to keep logs and be interviewed in a language of their choice. All except one of the interviews were conducted in English, by a researcher with no connections to the context of the respondent. The interview conducted in Arabic was translated into English prior to coding. Transcription and initial coding were undertaken by the interviewer with coding also undertaken by another researcher to provide checking and increase confidence in the results. Initial coding identified key themes which were discussed amongst the research team before being finalised. Word clouds were created from transcripts to identify key words and phrases used by participants and support coding decisions. Quotations were selected to provide detailed accounts of experience ('thick descriptions') which make the patterns of social and cultural relationships explicit and provide sufficient knowledge for the reader to make judgments regarding transferability (Lincoln and Guba, 1985; Geetz, 1973).

It was considered important to surface and acknowledge the researchers' own experiences as part of the project, so these were captured through reflective dialogue. The 
researchers all had experience of cross-cultural supervision in a UK/Saudi context, having worked together as a supervisory team on the EJSP programme, and they have extensive independent experiences of supervision across other contexts and a range of modes of study: they were part of the 'research world' (Lincoln and Guba, 1985). The reflective dialogue was analysed as outlined above and evidence from the dialogue is included in the findings below. The transcript of the reflective dialogue informed coding decisions and discussion of other issues raised by the data.

The project adhered to local ethical guidance and participation was voluntary. All data were recorded and analyzed anonymously, with any identifiers (e.g. names of institutions) removed. Mindful of ethical issues which might emerge, and which were also raised by Acker (2011), none of the student participants were our own PhD students.

Three key questions guided the research:

- What issues of shared (mis)understanding arise during cross-cultural supervision?

- What are the benefits and challenges of using technology for cross-cultural supervision?

- $\quad$ How does cross-cultural supervision contribute to the personal and professional development of students and supervisors?

These questions aimed to provide insights into the expectations that students and supervisors bring to cross-cultural supervision, to surface issues around language and processes for communication, and allow exploration of opportunities arising from the supervision experience.

\section{Findings and discussion}

\section{Expectations and mutual (mis)understandings}

In distance cross-cultural $\mathrm{PhD}$ supervision students and supervisors come from different perspectives, with different academic experiences and contexts, and with unique lived cultural experiences. It is not surprising that there are many opportunities for misunderstandings. Data from this study suggest two key areas where misunderstandings may arise: as a result of working in and across different languages, and due to the manner and type of feedback. Underpinning both of these areas are challenges resulting from different academic experiences and expectations.

\section{Language}

Difficulties related to working across different languages were reported by all respondents in this study. For two students and one supervisor they were mentioned only occasionally, but for one student and one supervisor (UK Supervisor) the challenges of working in different languages had been significant.

One area of difficulties was with writing in English where this was not the student's first language. Student A was reluctant to communicate with her external supervisor by email in case her written language caused misunderstandings. 
'I started to learn the English language three years ago and it is not easy to write scientific research with another language perfectly and without errors. This matter makes me anxious so much, even when I send [supervisor] emails.' (Student A)

Student $\mathrm{C}$ also described writing difficulties, which for her included finding an appropriate academic voice and writing for someone in a different culture. She expressed anxiety about the high expectations of the UK academic system and identified a need for supervisor support. She explained some of the challenges she faced and linked together issues associated with the need to translate or transfer ideas between languages, including the effort required for translation and challenge of writing succinctly:

'The problem is I am not a native speaker. I had a very good, a full idea in my mind, but when I tried to translate it as written English it took a lot of effort from me to explain the idea.' (Student C)

There was evidence that students received additional support with writing, for example the Saudi supervisor reported that she would sit for hours and read 'every word and every sentence' and Student C used a professional proof-reader. The UK supervisor hoped to support the development of English language skills without developing a dependency on the supervisor for correction. The UK supervisor also acknowledged the complexity of inter-connections between culture, language, academic discipline and thinking. She considered that working in more than one language might be an advantage, for example by helping to scaffold thinking. She also emphasised the role of written language in providing evidence of the quality of thinking, and commented that ensuring this was challenging. She suggested that a student attempting to develop thinking, take notes and write in English might not be able to convey nuances or intended meaning clearly.

Student $\mathrm{C}$ also commented on different expectations her supervisors held for her writing, which she attributed to their cultural context and local expectations:

'my internal supervisor [... ] who had knowledge from the United States, usually told me that I am going direct to the point. [...] But my external supervisor asked me [for] a lot of details and asked for detail of every single thing. Only I see the problem I don't have to do it in [my university], only in UK [university].' (Student C)

It may be that for a UK supervisor, or for UK assessment purposes, additional details of the context were needed, but the issue here is that there were conflicting instructions from different supervisors, possibly underpinned by different organisational and cultural expectations of academic writing. In such a situation the student is caught in the middle and left unsure of what path to follow.

English was the language used most often by respondents for oral communication. The UK supervisor reported that supervision meetings defaulted to English. Student C faced some issues with communication in English but commented that her English speaking supervisor understood these as they were used to international students and spoke slowly, clarified points and checked understanding. These were actions which the student found to be helpful. Student $\mathrm{C}$ also reported other issues due to language differences. Because the language of her study was not the language of her supervisors, there was a need to translate samples of data for the supervisors' benefit. 
Finally, studying abroad is often seen an opportunity to develop language skills (JeongBae \& Sang-Soon, 2014). The UK supervisor felt that obtaining a PhD in a second language within a different cultural setting should be more highly regarded. However, being a remote $\mathrm{PhD}$ participant was considered by student $\mathrm{A}$ to be an impediment to language development due to the lack of opportunities for engagement and immersion within a community of researchers. Other issues may result from a lack of integration into the local postgraduate community. For instance, Acker (2001) found that Canadian distance students complained that they were not integrated into departments and did not know the faculty well enough to find a supervisor when required to do so following taught elements of their studies.

Winchester-Seeto et al (2014) identified language as one of eight 'intensifiers' that make cross-cultural supervision more challenging than supervision in other international contexts. They identified similar and related issues to those found in this study, for example related to writing speed, speed of understanding and response, skills in negotiation and difficulties in conveying meaning in nuanced rather than blunt ways where language skills are limited.

However, findings from this study add some additional challenges, particularly those around the language of research implementation and differences in expectations, and also highlight some benefits and achievements related to the use of different languages. It should also be noted that academic writing skills will probably improve over time and with appropriate supervisory support. Improvements have been identified in other studies, for instance in an investigation into the experiences of international PhD students in Australia (Jeong-Bae \& Sang-Soon, 2014).

\section{Feedback}

Some of the findings identified in the section above link to issues of feedback. Differences in expectations regarding feedback, issues around the nature of feedback and difficulties with timescales emerged from the student data. However, feedback was not raised as an issue by supervisors.

Students made links between instruction and feedback. They expected both to be clear and helpful, but felt this was not always the case. Student A reflected that feedback made her 'feel lost' when the supervisor was trying to encourage a more self-directed approach to her study. She expected detailed feedback and instead felt that she was given general 'unhelpful' comments:

"The thing that was very difficult for me was the way of guidance and the way of providing feedback... from the beginning when I ask her a question about anything she used to reply with a question then she said have you read that paper or the other.. she sometimes provides me with the name of an author and ask me to read without telling me about anything like the title of the book.' (Student A)

Student $\mathrm{C}$ also commented on challenges faced when responding to feedback on written work:

'I told [my external supervisor] [...] when you give me ... feedback or a comment on a paragraph... you think that I can change it or correct it in a few days. But because I'm writing in and reading in a different language it took months to correct each comment.' (Student C)

Power balance in the relationships played a part in the perception of the feedback process. Student B had a very different experience from Student C. She received very detailed and 
precise feedback but felt that her supervisor was controlling her. Like Student A, who felt 'lost' in the face of feedback, power clearly resided with the external supervisor. For Student $C$ the successful upgrade gave her the confidence to challenge this underlying power structure.

Ali, Watson and Dhingra (2016), who investigated attitudes towards supervision, suggested that supervisors should provide timely and constructive feedback. Findings from this study highlight that in a distance, cross-cultural setting, students may not always perceive supervisors' feedback as helpful. There appears to be a need for a supervisor to achieve a balance between being overly prescriptive (as for student B) and insufficiently specific in their feedback (as for student A and C). Issues of power appear to have an impact on students, and measures may also be needed to ensure that student agency and confidence is developed, and the supervisor is not always seen as the 'boss' (Guerin \& Green 2015). In this study, mismatches in expectations and practices around feedback appear to have resulted, in part, from the different contexts of the participants and this highlights the need for all to be mindful of setting agreed expectations. It may also be useful for supervisory teams or institutions to agree procedures for managing differences of opinion within feedback processes. In cross-cultural settings a shared understanding between supervisors of how best to support the student in a new and different academic culture is needed and it would be helpful for tutors to be more open about their pedagogy of support.

\section{Technology}

Communication and interaction in distance supervision needs to be as robust as in face-to-face settings (Wisker, Robinson \& Shacham, 2007). Telephone calls are an option, but in all cases in this study, additional tools were used. These included emails, Skype, web conferencing (Collaborate, Elluminate), instant messaging and social networking tools. Table 3 considers the technologies used by respondents. The two main purposes for technology identified were 1) sharing files and documents and 2) for supervisory meetings.

<insert Table 3 here>

Student C's experiences illustrate how technology use changed over the duration of her studies. At the start of her PhD she had face-to-face contact with her external supervisor whilst she attended University in person. After 6 months, when she had returned home, short discussions were held twice a month by Skype. After 3 years the frequency of online interactions had decreased, and were complemented by regular face-to-face discussions with her local supervisor:

'her office is very close to my own in the University and usually every week I meet her and we have a very short and general discussion if there are questions or any queries.' (Student C)

For sharing documents, the UK supervisor was a regular user of Dropbox, finding it valuable for the exchange of documents and data, and for synchronous working.

'I use Dropbox ... so I can share ... students put documents ... we can work on documents together ... so I use Dropbox a lot especially if there are a lot of attachments or if there is video data.' (UK supervisor) 
Whilst email was an alternative for document exchange, its use raised other issues, particularly related to confidence with written language and possibilities for misunderstanding:

'I was very hesitated about sending email, I was afraid that my English language might not help me for right expressions and [my supervisor] might misunderstand me.' (Student C)

Student C's hesitations may be related to confidence with language and writing. This is an issue which should be considered when establishing norms of communication and the technologies being used for supervision. A preference for oral communication rather than written was also noted amongst doctoral students by Kumar, Johnson and Hardemon (2013). In this study supervisors and students expressed some technology preferences. For instance, the UK supervisor described online sessions as 'fantastic'. She had a clear preference for technologies which enabled visual communication:

'I really like connecting ... being able to see somebody... so you also build kind of a relationship. [...] I think that is really important to be able to connect on a human level.' (UK supervisor)

However, Student C did not regard Skype as providing this kind of opportunity, and she preferred meeting in person:

'I don't like [Skype] like face-to-face meetings because, for me, I'm a very visual person. I would like to write everything in front of my supervisor to discuss everything by writing and everything like that. I suffered from this, but [communication] was just by Skyping.' (Student C)

Using technologies with a visual component (for example web conferencing or Skype) has been reported as offering opportunities for relationship building and the development of effective social presence (Cornelius, Gordon \& Schyma, 2014). Such tools support informal discussion and the development of personal knowledge between supervisors and students, without which problems may occur (Nasiri \& Mafakhari, 2015). However, in this study technologies with a visual component presented technical difficulties:

'I told [my supervisor] when we use Skype honestly I cannot hear what you say.' (Student A)

'We tried Facetime and stuff like this, but we had a problem [...] we had calling and calling back from Skype, Facetime, to phone call, until we managed to deal with each other.' (Saudi supervisor)

Student A also commented on local technical problems, which meant that communication via Skype was better abroad than in her home country. As the supervisor quotation above indicates, flexibility over technology, and even a retreat to telephone conversations may be necessary to address technical problems. An additional challenge for Student A was her supervisor's preferences:

'My senior supervisor was in [her] 70s she was not interested to use new technology.' (Student A) 
Supervisors and institutions appeared to have more power than students over technology related decisions, access to additional resources and support, and control over which systems were used. For instance, one supervisor valued the opportunity to employ multiple screens during supervision meetings to view both the student and documents under discussions, but it is not clear whether students had similar technologies available and were also able to have the same perspective. Differences in access to resources between supervisors were also reported as a potential issue, for example different institutions in different countries may subscribe to different online journals. Due to differences in status and power between supervisor and student, the quality of audio, which has been reported as an issue in other studies, may be difficult for a student to challenge within a supervisory relationship (Peacock et al., 2012).

One of the supervisors in this study pointed to the need to keep up-to-date with technological opportunities for distance supervision. In fact all parties in supervision need to have an understanding of the tools that are available, and the skills and resources to access them (Erwee \& Albion, 2011). Otherwise, as Nasiri and Mafakhari (2015) identified, differences in computer literacy between supervisor and student might limit the exchange of information between them.

The findings from this study suggest that technology offers opportunities and challenges for cross-cultural distance supervision. These suggest, in common with Erwee and Albion (2011), that flexibility is needed over the tools used, and this requires supervisors and students to have skills with a range of tools. Students were sometimes seen to 'defer' to supervisors' choices about technologies, which may in turn intensify inequalities in relationships when supervisors also have access to additional resources and support. Whilst the use of tools with video capacity provides opportunities for relationship building and visual communication, it may mask difficulties with written language that would be revealed if email was more freely used. Our findings suggest that open discussion of expectations around technology use, the alternatives that can be employed to overcome any problems faced, and the value of both written and oral communication may be beneficial in cross-cultural and distance settings.

\section{Personal and professional learning}

Findings from this study provide evidence of personal and professional learning for supervisors and students: as global citizens with enhanced intercultural understandings, about different academic systems and practices, and through the development of skills for their future professional lives.

\section{Developing cultural understandings}

The UK supervisor considered that developing an understanding of others was an expectation of her role in academia, and that engaging in cross-cultural supervision provided an opportunity to develop her understanding of being a global citizen, through sharing, discussing progress and insights with other supervisors:

'there is quite strong sense of multiculturalism I think among the supervisors and I often talk about in induction we need to be very careful about enabling people to feel part of learning about other culture as well as bringing their own culture with them.' (UK supervisor) 
She regarded the process as enriching, providing opportunities for supervisors and students to learn from the cultural context - about other perspectives and other ways of thinking and doing things. She commented that it was an 'opportunity to celebrate multiculturalism as a means of shaping ourselves as individuals', and one which allowed personal development as a global citizen.

Personal and professional development was supported by visits and exchanges. Student $B$ reported difficulties faced at the start of her project. She mentioned that prior experiences of the external supervisor might influenced her perception of the student's culture, however, these challenges were clearly overcome as time progressed:

'At the beginning [my external supervisor] judged me on things [that are] not in my personality... I did not like coming late or not delivering things on proper time.' (Student B).

Student $\mathrm{C}$ reflected on the value of visits for supervisor and student learning about cultural expectations. She appreciated her external supervisor's visit and the opportunity this afforded for engagement with her research context:

'Her visit was only one time in the second year... it was only five days ... but it was really very helpful... She did a full day observation in the same class I am doing my research' (Student C).

In addition, a good understanding of UK institutional expectations and processes was important to help Student $\mathrm{C}$ understand her supervisor's comments and feedback, as discussed earlier. The author's reflective conversation supported the finding that visits supported the development of shared understandings between student and supervisor, and provided an opportunity to correct erroneous views about culture.

In the authors' reflective conversation, similarities with respondent supervisors' comments about their motivation and development of cultural awareness were identified. The need for some understanding across cultures from the very beginning of the supervisory relationship was acknowledged, and whilst one of the team felt she had relevant experience on which to draw, others identified that there had been gaps in their cultural understandings. Visits were also identified as significant opportunities for development of cultural understanding and for insight into students' contexts.

The findings suggest that cross-cultural supervision can enhance understanding of a different cultures, but which needs care to ensure mutual understanding and shared expectations. Tran, Nguyen and Green (2017) advocate intercultural reciprocity, where supervisor and supervisee learn from each other: this requires some understanding of each other's cultural context. Early reciprocal discussion of cultural issues and visits have clear value in enhancing cultural appreciation and the development of effective intercultural practices.

\section{Learning about different academic systems and practices}

The Saudi supervisor commented on the opportunity provided by cross-cultural supervision to learn about different 'ways of thinking' through meeting other people. She considered supervision as a continuous learning process which provided learning about different academic systems and processes including expectations, processes, rules, and regulations: 
'I am enjoying the experience because I learnt, I learn along with the students. I'm learning the way, how they emphasise on everything, ... the way they discuss, the way they ask questions, all this is a good experience.' (Saudi supervisor)

This learning was perceived as useful when supporting other local students too. Student B commented on learning about UK procedures in university documentation, and on learning through the production of her own documentation, which she regarded as useful for skills development and practice:

'I think this is also a very good opportunity that when I had a lack or deficiencies in one of my skills I have access to the university and then they will provide me with something to solve this problem.' (Student B)

Examples of learning about different academic systems and practices from the experience were identified in this study, for example heightened awareness of cultural impacts within PhD processes, from the application stage onwards. Other learning about education systems was also identified, although it was acknowledged that this was 'probably still only scratching the surface'. Cadman (2000) identified reciprocal learning as necessary to help international postgraduate students and staff in Australia come to terms with the challenges presented by different academic conventions. This is also revealed in this study, although perhaps variable in quality and quantity for individual students and supervisors.

Useful professional learning which was helpful for other teaching contexts and work with international students was also reported. Insights included enhanced sensitivity to the issues that might be faced by other international students, understanding different pedagogical settings and the impact of these on students. Some strongly held perceptions and assumptions were noted as being difficult to shift: 'it's just so deeply engrained in your way of thinking and way of working, that every time I have to stop and think', and the diversity of the supervisory team was important to avoid 'mistakes which could have been upsetting, rude, or inappropriate'.

\section{Personal and professional benefits}

Both supervisors commented on the possible impact of cross-cultural supervision on the supervisee: including learning about language, development of professional capital and inspiration to become supervisors themselves. The UK supervisor identified that she had a role in the personal development of her supervisee through supporting her to develop and articulate her philosophical stance, and the development of new insight and knowledge.

Whilst student B noted that staying 'at home' to study had professional benefits - such as local networking and obtaining grants after completion - students commented on the difficulty of fully engaging with a wider community of $\mathrm{PhD}$ researchers from a distance. Student $C$ felt there was a need to 'sit and talk', be part of such a community. Student B identified that being unable to engage in the full experience of the external university was a disadvantage. Without opportunities for participation there could be feelings of isolation. The focus of her local $\mathrm{PhD}$ community discussions was administrative issues, and this contributed to her feeling that experience of supervision is different for off campus students: 
'I do not have community of PhD students ... I feel I am isolated ... Here we do have a group of PhD students in the joint supervision [programme] but all of our concerns are about administration issues ... we do share our concerns about administration issues ... ok I had sometimes to discuss and share data analysis experience with one of my friends... ok we tried... but it is still a feeling of being away from the atmosphere.' (Student C)

Student $\mathrm{C}$ noted that the value of supervision goes beyond the completion of a $\mathrm{PhD}$ and student B provided some specific examples of this. She felt that doing a $\mathrm{PhD}$ had raised the standard of her research and increased her self-reliance, confidence, and capability.

'now I know how to do research to high standard, I know how to plan it well alone on my own... because I did it all on my own in my PhD... I did not have anybody on my side... ok I had support... but all of the things doing the all of the stuff... I think I am more confident I am more capable.' (Student B)

Maritz and Prinsloo (2015) suggest that it is often assumed that the student is the only one learning in a supervisory relationship. However, all supervisors are engaged on a continuous journey which involves them learning about the 'social and political context of doctoral education and the 'rules of the game' (Halse, 2011, p. 560). Blass, Jasman and Levy (2012) remind us developing as a supervisor is a personal learning journey, and Elliot and Kobayashi (2018) suggest that supervising in cross-cultural context contributes to the personal and professional growth of the supervisors. Cross-cultural practice provides an opportunity for learning which takes the supervisor beyond their local context and requires examination of assumptions and expectations about PhD study. Our study adds to this and provides evidence that cross-cultural supervision requires supervisors and students to be willing to learn reciprocally about cultural issues and institutional differences to provide an effective climate for $\mathrm{PhD}$ supervision. Sharing knowledge of cultural issues early (preferably before supervision starts) and visits appear to be successful methods of supporting appropriate learning.

\section{Conclusions}

Whilst previous studies have tended to focus on difficulties for international students, this study sought to highlight some of the opportunities that can arise in cross-cultural supervision contexts, as well as challenges. The authors recognise that like any small-scale qualitative study, this research has limitations and it may be inappropriate to generalise from the findings. However, in line with the interpretivist approach the purpose of this study was to provide evidence for readers to make their own judgements regarding transferability. Specific issues with this study include the difficulty in finding and recruiting appropriate respondents from within a small population, and the exclusively female nature of the sample. The reticence of participants to contribute reflective accounts also resulted in a reliance on interview data, which has made validation of findings difficult. Alternative methods of data collection might be considered for further studies, for example narrative or phenomenological enquiries across the lifecycle of a PhD experience. Notwithstanding these limitations the data have enabled some rich insights into personal experiences and led to a focus on three specific areas: areas of potential mis(understanding), technology, and personal and professional development, and findings suggest a number of issues for considerations in distance cross-cultural supervision scenarios. These cover working in a second language, using technology to enhance the supervision experience, the benefits of exchanges and addressing cultural issues at an early 
stage. Table 4 summarises some of the opportunities and challenges that can arise in crosscultural supervision contexts.

<insert Table 4 here>

Strategies to overcome issues of misunderstanding and mis-matched expectations include visits, open discussion, and sensitivity to the student experience. Student B in our study sought to address the challenges she faced through the use of a $\mathrm{PhD}$ coach. She described this as a successful experience and reflected that engaging with her coach earlier in the PhD experiences would have saved her 'a lot of years and lot of bad moments'. Thus, whilst it would clearly be beneficial for the supervisory team to be able to address issues themselves, an additional strategy for consideration is the provision of independent coaches within or outwith the university context, who can provide a listening ear and independent advice. Orellana, Darder, Pérez and Salinas (2016) also suggest future research to 'identify student needs in relation to the different stages or moments of $\mathrm{PhD}$ research and should take into account the particular profile of the student, the characteristics of effective supervision for each of these stages, and support strategies for this supervision by making the most of the communicative advantages of technology'(p. 99).

The findings of this study highlight some of the opportunities for personal and professional learning, the need for cultural understanding and for student agency in decisions about supervision processes. In common with Manathunga (2014) our findings point to a need for supervisors to help to build $\mathrm{PhD}$ student confidence and agency. This will empower students within decision-making about issues such as methods of communication and ensure they have clarity about academic expectations and supervisors' roles and actions (e.g. around feedback). Supervision of PhD students at a distance brings additional challenges in understanding the different cultural contexts and expectations. The use of technology brings additional considerations such as how the mode of communication impacts on the supervision experience. There is a need then for students and supervisors to be more aware of these challenges as they embark on the research journey together.

6958 words (excluding abstract)

\section{References}

Abiddin, N. Z., Ismail, A. \& Ismail, A. (2011). Effective supervisory approach in enhancing postgraduate research studies. International Journal of Humanities and Social Science. 1(2). 206-217.

Ali, P. A., Watson, R. \& Dhingra, K. (2016). Postgraduate research students' and their supervisors' attitudes towards supervision. International Journal of Doctoral Studies. 11. 227-241

Acker, S. (2001). The hidden curriculum of dissertation advising. In E. Margolis (ed.) The hidden curriculum in higher education. New York: Routledge. 
Acker, S. (2011). Reflection on supervision and culture: what difference does difference make? Commentary. Innovations in Education and Teaching International. 48(4). 413-420.

Blass E., Jasman A. \& Levy R. (2012) Supervisor reflection on developing doctoralness in practice-based doctoral students. Quality Assurance in Education. 20(1) 31-41

Cadman K (2000) 'Voices in the air': evaluations of the learning experiences of international postgraduates and their supervisors. Teaching in Higher Education. 5(4) 475-491

Cornelius, S. (2014). The challenges of learner-centered teaching in virtual classrooms. In J. Viteli \& M. Leikomaa (Eds.), Proceedings of EdMedia: World Conference on Educational Media and Technology 2014 (pp. 1538-1544). Association for the Advancement of Computing in Education (AACE).

Cornelius, S., Gordon, C., \& Schyma, J. (2014). Live online learning: Strategies for the web conferencing classroom. Basingstoke: Palgrave Macmillan.

Cornelius, S. and Nicol, S. (2016) Understanding the needs of masters dissertation supervisors: supporting students in professional contexts. Journal of Perspectives on Academic Practice, 4(1).

Creswell, J. W (2009) Research Design Qualitative Quantitative and Mixed Methods Approaches. (Third edition). London: Sage Publications Ltd

Creswell, J. W. \& Miller, D. L. (2000) Determining Validity in Qualitative Inquiry, Theory Into Practice, 39:3, 124-130, DOI: 10.1207/s15430421tip3903_2

Erwee, R. \& Albion, P. (2011). New Communication Media Challenges for Supervisors and External Doctoral Students. In M. Koehler \& P. Mishra (Eds.), Proceedings of Society for Information Technology \& Teacher Education International Conference 2011 (pp. 252259). Chesapeake, VA: Association for the Advancement of Computing in Education (AACE).

Elliot, L. \& Kobayashi, S. (2018): How can PhD supervisors play a role in bridging academic cultures?, Teaching in Higher Education. 1-19. DOI: 10.1080/13562517.2018.1517305

Geetz, C. (1973) The interpretation of culture. New York: Basic Books.

Grant, B. \& Manathunga, C. (2011). Supervision and cultural difference: rethinking institutional pedagogies. Guest Editorial. Innovations in Education and Teaching International. 48(4). 351-354.

Guerin, C. \& Green, I. (2015) 'They're the bosses': feedback in team supervision, Journal of Further and Higher Education, 39:3, 320-335, DOI: 10.1080/0309877X.2013.831039

Halse, C. (2011) 'Becoming a supervisor': the impact of doctoral supervision on supervisors' learning. Studies in Higher Education. 36(5) 557-570. 
HESA (2019) Statistical Bulletin SB252: Higher Education Student Statistics: UK 2017/2018 Where students come from and go to study. https://www.hesa.ac.uk/news/17-012019/sb252-higher-education-student-statistics/location (accessed 26/1/19)

Jeong-Bae, S. \& Sang-Soon, P. (2014) Academic experiences of international PhD students in Australian higher education: From an EAP program to a PhD program, International Journal of Pedagogies and Learning, 9:1, 26-37, DOI: 10.1080/18334105.2014.11082017

Kumar, S., Johnson, M. \& Hardemon, T. (2013). Dissertations at a Distance: Students' Perceptions of Online Mentoring in a Doctoral Program. International Journal of E-learning and Distance Education. 27(10). Retrieved on 13/4/2017 from: http://ijede.ca/index.php/jde/article/view/835/1481

Lahenius, K. \& Ikävalko, H. (2012). Joint Supervision Practices in Doctoral Education- A Student Experience. Journal of Further and Higher Education. 38(3). 427-446.

Lincoln, Y. S. \& Guba, E. G. (1985) Naturalistic Inquiry. Newbury Park, CA: Sage Publications Manathunga, C. (2007) Intercultural postgraduate supervision: ethnographic journeys of identity and power. In Palfreyman D and McBride (eds.) Learning and teaching across cultures in higher education. Basingstoke: Palgrave Macmillan

Manathunga, C. (2014). Intercultural Postgraduate Supervision: reimaging time, place and knowledge. London: Routledge.

Maor, D., Ensor, J. D. \& Fraser, B. J. (2016) Doctoral supervision in virtual spaces: A review of research of web-based tools to develop collaborative supervision. Higher Education Research \& Development. 35(1). 172-188, DOI: 10.1080/07294360.2015.1121206

Maritz, J. \& Prinsloo, P. (2015) A Bourdieusian perspective on becoming and being a postgraduate supervisor: the role of capital. Higher Education Research and Development. 34(5) 972-985

Mcalpine , L. (2013) Doctoral supervision: Not an individual but a collective institutional responsibility. Infancia y Aprendizaje. 36(3). 259-280, DOI: 10.1174/021037013807533061

Nasiri, F. \& Mafakheri, F. (2015). Postgraduate research supervision at a distance: a review of challenges and strategies. Studies in Higher Education 40(10) 1962-1969

Nicol, S. \& Cornelius, S. (2017) Effective supervision of master's researchers in professional contexts. In Carter, S. and Laurs, D. (eds.) Developing research writing: a handbook for supervisors and advisors. London: Routledge (pp 125-132) 
Olmos-López, P. \& Sunderland, J. (2016): Doctoral supervisors' and supervisees' responses to co-supervision, Journal of Further and Higher Education, DOI: 10.1080/0309877X.2016.1177166

Orellana, M. L., Darder, A., Pérez, A., \& Salinas, J. (2016). Improving doctoral success by matching $\mathrm{PhD}$ students with supervisors. International Journal of Doctoral Studies, 11, 87-103. Retrieved from http://ijds.org/Volume11/IJDSv11p087-1030rellana1629.pdf

Palfreyman, D. (2007). Introduction: Learning and teaching across cultures in higher education. In Palfreyman, D. and McBride (eds.) Learning and teaching across cultures in higher education. Basingstoke: Palgrave Macmillan.

Peacock, S., Murray, S., Dean, J., Brown, D., Girdler, S. \& Mastrominico, B. (2012). Exploring tutor and student experiences in Online Synchronous Learning Environments in the Performing Arts. Creative Education. 3(7). pp. 1269-1280.

Pratt, ML (1992) Imperial Eyes: Travel Writing and Transculturation. London: Routledge Pyhältö, K., Vekkaila, J., \& Keskinen, J. (2012). Exploring the fit between doctoral students' and supervisors' perceptions of resources and challenges vis-à-vis the doctoral journey. International Journal of Doctoral Studies, 7, 395-414.

Trahar, S. (2011). Introduction: global stories of courage, knowledge and unbecoming. The Doctorate: international stories of the UK experience. Discussions in Education Series. ESCALATE. HEA, Bristol https://www.heacademy.ac.uk/system/files/8137.pdf (accessed 26/1/19)

Tran, L., Nguyen, L. \& Green, W (2017) Enhancing the Experiences and Outcomes of International Higher Degree Research Candidates: Reciprocal Intercultural Supervision. IERN https://www.ieaa.org.au/documents/item/1036 (accessed 26/01/2019)

Whitten, P. \& Hunter, D. E. K. (1992). Anthropology: Contemporary Perspectives. London: Longman.

Winchester-Seeto T, Homewood J, Jacenyik-Trawoger C, Manathunga C, Reid, A. \& Holbrook, A. (2014) Doctoral supervision in a cross-cultural context: issues affecting supervisors and candidates. Higher Education Research and Development 33(3) 610-626

Wisker, G., Robinson, G. \& Shacham, M. (2007). Postgraduate research success: Communities of practice involving cohorts, guardian supervisors and online communities. Innovations in Education and Teaching International, 44(3), 301-320. 
Table 1. Student interviewees

\begin{tabular}{|l|l|l|l|l|}
\hline & PhD study topic & $\begin{array}{l}\text { Language of } \\
\text { previous studies }\end{array}$ & $\begin{array}{l}\text { Country of previous } \\
\text { study }\end{array}$ & $\begin{array}{l}\text { Year of } \\
\text { PhD study }\end{array}$ \\
\hline Student A & $\begin{array}{l}\text { Education: } \\
\text { Educational } \\
\text { Administration }\end{array}$ & Arabic & $\begin{array}{l}\text { Local universities in } \\
\text { Saudi Arabia }\end{array}$ & 4 \\
\hline Student B & Pharmacy & English & $\begin{array}{l}\text { Local universities in } \\
\text { Saudi Arabia }\end{array}$ & 4 \\
\hline Student C & $\begin{array}{l}\text { Education: } \\
\text { Instructional } \\
\text { technology }\end{array}$ & Arabic & $\begin{array}{l}\text { Local universities in } \\
\text { Saudi Arabia }\end{array}$ & 3 \\
\hline
\end{tabular}

Table 2. Supervisor interviewees

\begin{tabular}{|l|l|l|l|}
\hline & Discipline & $\begin{array}{l}\text { Academic } \\
\text { qualifications }\end{array}$ & $\begin{array}{l}\text { Experience of doctoral } \\
\text { supervision }\end{array}$ \\
\hline Supervisor -UK & $\begin{array}{l}\text { Education: } \\
\text { Linguistic }\end{array}$ & $\begin{array}{l}\text { Degree and PhD from } \\
\text { UK. European } \\
\text { Diploma }\end{array}$ & $\begin{array}{l}\text { Over 25 doctoral students, } \\
\text { including many at a distance }\end{array}$ \\
\hline $\begin{array}{l}\text { Supervisor- } \\
\text { Saudi }\end{array}$ & $\begin{array}{l}\text { Education: } \\
\text { Computer } \\
\text { education }\end{array}$ & USA degree and PhD & Supervised 2 EJSP students \\
\hline
\end{tabular}

Table 3. Respondents' use of technology for communication and interaction

\begin{tabular}{|l|l|l|}
\hline Technology & Purpose & Issues reported \\
\hline Email & $\begin{array}{l}\text { Questions and clarifications } \\
\text { Arranging meetings } \\
\text { Sharing files }\end{array}$ & $\begin{array}{l}\text { Reliance on written language } \\
\text { Possibility for misunderstandings } \\
\text { Not always suitable for sharing large files }\end{array}$ \\
\hline Skype & Meetings & $\begin{array}{l}\text { Problems with quality of audio } \\
\text { Reliability of service }\end{array}$ \\
\hline Dropbox & $\begin{array}{l}\text { Sharing large files } \\
\text { Working on documents } \\
\text { together }\end{array}$ & None reported \\
\hline Phone & Meetings & Cost \\
\hline $\begin{array}{l}\text { Web } \\
\text { conferencing }\end{array}$ & Meetings & $\begin{array}{l}\text { Recording possible } \\
\text { Permits note taking }\end{array}$ \\
\hline Facetime & Meetings & Technical problem \\
\hline
\end{tabular}


Table 4. Opportunities and challenges that can arise in cross-cultural supervision contexts

\begin{tabular}{|c|c|}
\hline Theme & Issues \\
\hline $\begin{array}{l}\text { Undertaking a research } \\
\text { degree in a second } \\
\text { language is both a barrier } \\
\text { and enabler in the learning } \\
\text { experience }\end{array}$ & $\begin{array}{l}\text { - completing a PhD in a second language is an undervalued } \\
\text { achievement } \\
\text { - working across languages provides access to different ways } \\
\text { of thinking and expression which can deepen understandings } \\
\text { - students have anxieties about writing, and may find it } \\
\text { difficult to reach the standards they perceive as expected in } \\
\text { other academic cultures } \\
\text { - language issues may impact on cross-cultural supervision in } \\
\text { particular ways, for example requiring additional translation } \\
\text { not necessary otherwise } \\
\text { - distance PhD students may miss out on opportunities for } \\
\text { language development available to other international } \\
\text { candidates } \\
\text { - supervisors should work together (and with students) to } \\
\text { clarify expectations for feedback to ensure common } \\
\text { understandings of purpose and process }\end{array}$ \\
\hline $\begin{array}{l}\text { Supervision at a distance } \\
\text { can be enhanced through } \\
\text { suitable choices and } \\
\text { discussion of the use of } \\
\text { web-based technology }\end{array}$ & $\begin{array}{l}\text { - discussion of technology choices and use is necessary to } \\
\text { ensure equity and allow flexibility to overcome potential } \\
\text { problems } \\
\text { - the use of video (e.g. webcams) supports informal } \\
\text { communication and relationship building } \\
\text { - the use of technologies which enable both oral and written } \\
\text { communications is important to allow rounded development } \\
\text { of language skills and support effective interactions }\end{array}$ \\
\hline $\begin{array}{l}\text { There is a need for } \\
\text { reciprocity in cross-cultural } \\
\text { supervision teams and } \\
\text { exploration of cultural } \\
\text { understandings }\end{array}$ & $\begin{array}{l}\text { - students and supervisors will gain personally and } \\
\text { professionally from cross-cultural supervision experiences } \\
\text { - cultural learning is ideally facilitated through visits and } \\
\text { exchanges } \\
\text { - learning related to academic cultures and expectations may } \\
\text { benefit supervisors' other students } \\
\text { - learning about cultural issues should be considered early in, } \\
\text { or preferably before, the PhD process to avoid } \\
\text { misunderstandings. }\end{array}$ \\
\hline
\end{tabular}

